Article

\title{
Time or Money? The Influence of Warm and Competent Appeals on Donation Intentions
}

\author{
Yong Zhang, Chuling Lin * and Jialing Yang \\ School of Management, Jinan University, Guangzhou 510632, China; tzhyong@jnu.edu.cn (Y.Z.); \\ karineyang@163.com (J.Y.) \\ * Correspondence: linchulingcl@163.com; Tel.: +86-13128532017
}

Received: 17 October 2019; Accepted: 4 November 2019; Published: 7 November 2019

\begin{abstract}
Charitable donations are important for healthy functioning and the sustainable development of our society. Individuals are making great contributions by donating their money or volunteering their time. Previous studies have discussed advertising strategies to promote either money or time donation. However, few have focused on money and time donation in one study or compared the effectiveness of advertising strategies to promote different types of donations. To promote an individual's participation, this paper explores the role of advertising appeals in donation intentions. From the perspective of social cognition, this paper examines the influence of warm and competent advertising appeals on an individual's donation intentions of time and money based on trait activation theory, revealing the underlying mechanisms. The results show that under the warm advertising appeal conditions, individuals are more willing to donate time due to the mediating role played by social connectedness. In contrast, under the competent advertising appeal conditions, individuals are more willing to donate money due to the mediating role played by competitive orientation. The implications and limitations are also discussed in this paper.
\end{abstract}

Keywords: advertising appeal; donation intention; social connectedness; competitive orientation

\section{Introduction}

People can promote social sustainability through various ways, such as purchasing environmentally-friendly products to protect the environment, taking public transportation to cope with global warming or conserving wildlife and nature to maintain biodiversity [1]. Charitable donation is also an important means to deal with multiple social issues, including culture, art, environment, education, women's issues, children's issues and poverty [2], promoting healthy functioning and sustainable development of the society [3]. Recently, with the growing popularity of online donation platforms and mobile payment, it is more convenient for individuals to gather information about charitable activities and make donations for social causes. They participate in charitable activities by donating their money or volunteering their time, making great contributions to social causes and social sustainable development. It is estimated that $70 \%$ of total charitable giving comes from individuals in the U.S. in 2017 [4]. However, donations from individuals still account for an insignificant share, especially in developing countries [5]. In China, only $23.28 \%$ of total charitable giving came from individuals in the same year [6]. Therefore, it is necessary to explore effective measures to promote an individual's participation in donation.

Faced with a growing need, shrinking government support and intensifying competition [7], nonprofit organizations are adopting charitable advertising as an important means to increase charitable donations [8]. Previous research on charitable advertising has discussed effective strategies to increase donation intentions. They focused on altruistic/egoistic appeals $[3,9,10]$, positive/negative emotional appeals [11,12] and abstract/concrete appeals [13], and examined the effectiveness of these appeals by 
considering the influence of donators characteristics and situational contexts. Some research has noted warm appeal, which they regard as a kind of positive emotional appeal $[12,14]$. Warmth is one of two fundamental dimensions in social cognition with competence as another [15]. Nevertheless, competent appeals gain less attention than warm appeals, both in a theoretical and a real marketing context. In the real marketing context, individuals are used to thinking of charity advertisings with warm appeal, such as the advertising slogan "love together" on 99 public welfare day initiated by Tencent Public Welfare Platform. However, charitable advertisings with competent appeal are also adopted by organizations. For example, the Qingsongchou Public Welfare Platform designs their charitable advertisings with the slogan "Give every family the courage and strength to cope with illness", which emphasizes the dimension of competence. Consequently, by introducing the two fundamental dimensions of social cognition into charity advertising, we are able to identify warm appeal and competent appeal in charitable advertisings and explore their influence on donation intentions.

More importantly, donations are often made in two forms: Time donation and money donation. Previous studies have discussed either time donation or money donation, focusing on the factors influencing donation intentions of one resource type [16-20]. Few studies have considered time donation and money donation simultaneously $[13,21]$. Due to the psychological differences between time and money [22,23], it is necessary to differentiate a donation intention of time from that of money, so as to develop more effective advertising strategies. As a result, in this paper we explore the role of advertising appeals in donation intentions of different resources and reveal their underlying mechanisms. Specifically, based on trait activation theory, we propose that different advertising appeals significantly influence an individual's donation intention of different resources. Exposure to warm advertising appeal increases individuals' intentions to donate time, in which social connectedness plays a mediating role. In contrast, exposure to competent advertising appeal increases individuals' intentions to donate money, in which competitive orientation plays a mediating role.

The rest of this article is organized as follows: Section 2 provides the overviews of the literature and describes the hypotheses. Section 3 describes experiment 1 , which examines the influence of advertising appeals on donation intentions. Section 4 describes experiment 2 , which examines the influence of advertising appeals on donation intentions as well as the underlying mechanism. Section 5 concludes and discusses the article.

\section{Literature Review and Hypotheses Development}

\subsection{Advertising Appeals in Charitable Advertising}

An advertising appeal refers to the prominence and emphasis of different kinds of information that the advertiser attempts to deliver to their target audiences so as to catch the audience's attention and persuade or impress the audience [24]. An advertising appeal is the core element in advertising content, which determines the persuasive effectiveness of advertising [25].

Previous research has identified multiple types of charitable advertising appeals. Among them, other-benefit and self-benefit appeals, also used as altruistic and egoistic appeals, are the most widely studied typology in the literature on charitable advertising. An other-benefit appeal frames the message by emphasizing the benefits for those in need, whereas a self-benefit appeal frames the message by emphasizing what the giver will gain [3]. Both of them can promote charitable behaviors, while the relative effectiveness varies between situational contexts. For instance, relative effectiveness depends on whether the nature of donation setting is public or private [9], or whether the social culture is masculine or feminine [26]. Individual characteristics can also affect the effectiveness of other-benefit appeal and self-benefit appeal. For instance, females hold a more favorable attitude towards the help-others appeal and males view the help-self appeal more favorably [8]. Individuals with strong beliefs in karma respond less favorably to self-benefit appeals [10]. Apart from other-benefit/self-benefit appeals, another appeal drawing great attention is the emotional appeal, which can be categorized into positive appeal and negative appeal based on the emotional valence. The valence of emotional appeal 
can be manipulated by image or message. For example, adverts depicting victims with a sad facial expression are more effective in eliciting prosocial behavior compared to those depicting victims with a happy facial expression [27]. Negatively-framed messages emphasizing negative consequences of donation (e.g. 'Without your help ...' ') are more attention-grabbing and persuasive compared with positively framed messages emphasizing positive consequences of donation (e.g. 'With your help ... ') [11,12]. It has been demonstrated that a negative appeal can evoke negative emotions such as guilt, distress, upset, worry, empathic concern; in order to avoid or reduce these negative emotions, individuals attempt to help others [11,21]. Conversely, positive appeals can increase the perceived impact of behavior by presenting the potential positive consequences, thus increasing the donation intentions [28,29]. Moreover, some scholars identified abstract appeal and concrete appeal based on construal level theory. They pointed out that abstract appeals increased time donation intentions, whereas concrete appeal increased money donation intentions [13].

Some scholars have noted the warmth in advertising. However, in their studies, advertising with a warmth appeal is regarded as a kind of positive emotional appeal based on the emotional valence, with negative emotional appeal (e.g., guilt appeal) considered its opposite [12,14]. In social cognition theory, warmth is one of the two fundamental dimensions in people's perception and judgment, while competence is another dimension [15]. The competent appeal has gained little attention compared to the warm appeal, but it is actually adopted by charitable organizations in reality. Although some scholars have already applied both of these social cognition dimensions into advertising research, they focused on the warm and competent advertising strategies in business contexts [30], or donators' perceived warmth and competence after viewing charitable advertising [18]. Little research has studied the advertising itself that uses warmth and competence in charitable advertising.

In this study, we introduce two fundamental dimensions of social cognition into charitable advertising. According to the difference in the message delivered by charitable advertisements, we identified warm appeal and competent appeal. Specifically, as the warmth dimension of social cognition captures the perception of friendliness, well-intention, trustworthiness, warmth, good-nature and sincerity, we defined warm appeals in charitable advertisings, which transfer the message about friendliness, being sociable, morality, caring, and communion, expressing and delivering ideas, themes, content or information about good intention or goodwill [31,32]. In contrast, as the competence dimension of social cognition captures the perception of confidence, capability, efficiency, intelligence and skill, we defined competent appeals in charitable advertisings, which transfer the message about capabilities, effectiveness, efficiency, industriousness and intelligence, expressing and delivering ideas, themes, content or information about the ability to achieve an intention [31,32]. Furthermore, we will discuss the relative effectiveness of warm and competent appeals to time donation money donation.

\subsection{Advertising Appeals and Donation Intentions}

Previous studies have discussed the donation of time or money [16-20]. Time and money are valuable resources, but donors view them as quite different from each other [21]. It has been demonstrated that thinking about time and thinking about money may result in distinct psychological consequences. Moreover, consumers show different perceptions and behaviors when they spend time or money [22,23]. With the differences between spending time and money on donation, it is necessary to explore when advertising appeals for money and time will be relatively more effective. According to trait activation theory, situational cues can activate trait-associated constructs [33]. Once these traits are activated, individuals will seek to reinforce these traits through behaving in a manner consistent with them [34]. For example, requiring participants to write the words related to morality or to watch a picture featured morality activates their moral identity, resulting in higher willingness to make contributions in the subsequent donation task [20]. We propose that warm and competent advertising appeals can activate different trait-associated constructs, which influences individuals' intentions to donate different resources. 
The warmth dimension in social cognition captures traits that are related to perceived intent, including friendliness, helpfulness, sincerity, trustworthiness and morality [15]. People with warm traits demonstrate a motivation to be other-focused and behave consistent with moral codes [35]. According to the trait activation theory [33], exposure to a warm advertising appeal activates the constructs related to the warm trait in the mindset, guiding individuals to behave in accordance with the warm trait. Therefore, after viewing the advertising with warm appeal, individuals may tend to be other-focused and behave morally in the sequent donation decision. Compared to money donation, which involves reduced social interaction, time donation involves more direct interaction with others, creating stronger interpersonal connections and other-focused behaviors [36]. Additionally, because of the direct connection and interaction with others, giving time is also perceived as a more 'moral' act than giving money when the value of the two resources is equivalent [7]. Consequently, when individuals are exposed to the warm appeal, they are more willing to donate time than money.

In contrast, the competence dimension in social cognition captures traits that are related to perceived ability, including intelligence, skill, creativity and efficacy [15]. A competent person has the ability to execute his/her intentions [35] and put emphasis on improving self-esteem and self-value $[37,38]$. Therefore, according to the trait activation theory, exposure to competence appeal activates the constructs related to the competent trait in their mindsets, guiding individuals to be self-focused and pursue the maximum utility in sequent donation decision. Donations require resource investments of time or money, both of which impose a particular kind of opportunity cost [20]. In nature, time is a kind of unique resource with an ultimately finite supply, whereas money is a kind of fungible resource which can be regained once it is lost [39-41]. On the one hand, since time is less fungible than money, losing time tends to be more painful than losing money [42]. Thus, money donation requires less effort and psychological/behavioral investment than time donation [43]. On the other hand, due to the fact that the measurement of time is more ambiguous than of money, individuals do not account for how they spend their time as effectively as money [44]. Budgeting for time is more difficult and may generate greater and more frequent planning fallacies than money [45]. Consequently, when individuals are exposed to the competent appeal, they are more willing to donate money than time.

Taken together, we propose the following hypotheses:

Hypothesis 1a. Warm advertising appeals (vs. competent advertising appeals) are more effective in increasing individuals' intentions to donate time than donate money.

Hypothesis $\mathbf{1 b}$. Competent advertising appeals (vs. warm advertising appeals) are more effective in increasing individuals' intentions to donate money than donate time.

\subsection{The Mediating Role of Social Connectedness and Competitive Orientation}

Social connectedness and competitive orientation reflect individuals' interpersonal orientations coping with others. We posit that different advertising appeals strengthen different interpersonal orientations, which in turn affects donation intentions of time and money.

Social connectedness refers to the emotional distance or connection between self and others [46]. The need for social connectedness motivates individuals to strive to fit in social groups, engage in more actions that promote social harmony and show respect for social norms [47]. Previous studies indicated the positive relationships between social connectedness and prosocial behaviors. For example, the higher level of social connectedness is, the greater the probability for individuals to donate to charity and engage in volunteering [48]. Similarly, individuals with a stronger need for connectedness will be more generous when confronted with calls for help from needy others [49]. Cojuharenco et al. pointed out that the sense of connectedness to others can increase perceived effectiveness of actions, thereby promoting more socially responsible behaviors [50]. In this study, exposure to a warm appeal can activate warm-related concepts in the mindset, resulting in more attention on others, greater tendency 
to help others and relationship establishment with others. Thus, the needs for social connectedness are enhanced. Donating time or money serves as a way to satisfy the increased need for social connectedness, providing individuals with the opportunities to approach others. Money is more related to self-sufficiency and interpersonal disconnection, whereas time is more related to social connection and it encourages social engagement [36]. Compared to money donation, time donation involves more direct connection with others. It is, thus, more likely to be regarded as a moral act [51], better meeting the needs for social connections. Consequently, exposure to the warm appeal enhance individuals' needs for social connectedness, which in turn increases their intentions to donate time.

Competitive orientation represents an individual's competitive attitude towards the relationship between the self and others in the social environment [52]. Individuals with competitive orientation have the tendency to maximize the difference between the outcomes of their own and others in their social environment [53], and expect more than others in terms of social motivation [54]. They also concentrate on the competition for resources [55] and prefer making decisions toward advancing their own welfare [56]. Previous studies have demonstrated that competence is associated with competition. For example, when competence or competence-related concepts are activated, individuals behave more competitively in the sequent allocation tasks [57]. Perceived competence is the intrinsic motivation of competitive behaviors [58]. In this study, exposure to a competent appeal can activate competence-related concepts in the mindset, which are associated with effectiveness, efficacy and ability, resulting in a greater focus on the self. Pro-selfs have a different perception to pro-socials on cooperation-competition dimensions [59]; they attempt to maximize self-benefits and tend to be competitive [60]. Therefore, individuals' competitive orientations were strengthened after viewing advertising with competent appeal. Individuals with a strong competitive orientation put emphasis on self-distinctiveness. In order to better achieve self-evaluation, more social comparison information is required [61]. Since the measurement of time is more ambiguous than that of money [44], donating money is more accountable and comparative than donating time for the purpose of self-distinctiveness. Moreover, time is less fungible than money [42]. In other words, time cannot be regained once it is lost, whereas money is possible to be exponentially increased [20]. Thus, competitive-oriented people who attach importance on their own welfare are more likely to donate money instead of the unique resource of time. Consequently, exposure to the competent appeal strengthens individuals' competitive orientations; with the influence of competitive orientation, individuals increase their intentions to donate money.

To summarize, we propose that both social connectedness and competitive orientation will mediate the influence of different advertising appeal on donation intentions of different resource. However, different types of advertising appeal will strengthen different orientations. Specifically, warm advertising appeals strengthen individuals' social connectedness, thereby increasing their donation intentions of time. In contrast, competent advertising appeals strengthen individuals' competitive orientation, thereby increasing their donation intentions of money. Taken together, we propose the following hypotheses:

Hypothesis 2a. Social connectedness mediates the influence of warm advertising appeals on individuals' donation intentions of time.

Hypothesis $\mathbf{2 b}$. Competitive orientation mediates the influence of competent advertising appeals on individuals' donation intentions of money.

\section{Study 1: The Influence of Advertising Appeals on Donation Intentions}

The purpose of Study 1 is to test the influence of different advertising appeals (warm appeal vs. competent appeal) on different types of donation intentions (time donation vs. money donation). 


\subsection{Pretest}

Before the formal experiment, we conducted a pretest to determine the charitable organization and charitable project used as the experiment material in the formal experiment. In terms of charitable organization, we invited participants to rate their familiarity with the charitable organizations and select the one with the highest familiarity rate as the experiment material. The list of the charitable organizations comes from the top five most searched charitable organizations in Baidu Search (i.e., One Foundation, Red Cross Society of China, Tencent Charity Foundation, World Wide Fund for Nature, Chinese Young Volunteers Association). We recruited participants from a Chinese online panel (https://www.sojump.com/) that is similar to Mturk Prime in March 2019. Twenty-five participants with various backgrounds took part in this pretest and completed the survey $(61.5 \%$ male; $53.8 \%$ were 26 to 30 years old). They were asked how familiar they were with each charitable organization on a 7-point scale $(1=$ very unfamiliar, $7=$ very familiar). Results showed that participants were most familiar with Red Cross Society of China $\left(\mathrm{M}_{\text {Red Cross Society of China }}=5.20, \mathrm{SD}=1.63 ; \mathrm{M}_{\text {One Foundation }}=4.56\right.$, $\mathrm{SD}=1.53 ; \mathrm{M}_{\text {Tencent }}$ Charity Foundation $=5.00, \mathrm{SD}=1.19 ; \mathrm{M}_{\text {World Wide Fund for Nature }}=4.24, \mathrm{SD}=1.85$; $\mathrm{M}_{\text {Chinese Young Volunteers Association }}=4.92, \mathrm{SD}=1.53$ ). Therefore, Red Cross Society of China was selected as the experimental material. In terms of charitable project, according to the Annual Report on China's Charitable Donation 2017, donations for disaster relief, medical health, education, poverty alleviation and other fields have drawn great social attention [6]. Therefore, disaster relief was selected as the theme of charitable project.

\subsection{Experimental Design and Subjects}

A 2 (advertising appeal: warm vs. competent) $\times 2$ (donation type: time vs. money) between-subjects quasi-experimental design was used in this study. Participants were randomly assigned to one of the four conditions. We conducted this experiment in the library of Jinan University in March 2019, where questionnaires were distributed and collected. One hundred and fifty-five students participated in the experiment in exchange for payment. After removing six participants for failing to complete the questionnaire, a total of 149 valid questionnaires were collected (36 for warm-time condition, 37 for warm-money condition, 42 for competence-time condition, and 34 for competence-money condition). Among them, the age of participants was mainly between 18 and 25 years old, accounting for $78.5 \%$. There were 83 females $(55.7 \%)$ and 66 males $(44.3 \%) ; 44$ undergraduates (29.5\%), 95 graduate students $(63.8 \%)$ and 10 others $(6.7 \%)$.

\subsection{Experimental Procedures}

First, participants were required to read the advertising and then rate the advertising on a warmth-competence scale. Adapted from Zawisza and Pittard, warmth and competence of the advertising was manipulated via the vocabularies used in them [30]. Participants were given background information first. They read the introduction of the project: "Red Cross society of China has initiated a charitable project for disaster relief, involving raising funds for rescue and carrying out some voluntary services, so as to alleviate the suffering of the victims." Then, participants were presented with an advertisement published online by this project as follows:

In the warm appeal condition, participants read, "all kinds of serious disasters threaten people's survival and security, resulting in great pain and loss. Although disasters are unavoidable and often occur in sudden, all walks of society can unite and bring love and hope together, passing on the social warmth to resist disasters. Give out your helping hands and help the victims in the disaster-hit area to get through the difficulties!"

In the competent appeal condition, participants read, "all kinds of serious disasters threaten people's survival and security, resulting in great pain and loss. Although disasters are unavoidable and often occur in sudden, all walks of society can exhibit great courage and confidence to resist disasters. Give out your powerful hands and help the victims in the disaster-hit area to get through the difficulties!" 
After viewing the advertisement, participants were asked to rate the advertising on the warmth-competence scale adapted from Kervyn et al. for manipulation check [32]. Specifically, they were required to indicate the degree to which they perceived the appeal they had viewed was warm (three items: warm/ friendly/ sincere) and competent (three items: competent/ powerful/ confident) on 7-point scales ( $1=$ not at all, $7=$ very much).

Secondly, participants were asked to indicate their donation intentions. Specifically, they were told that Red Cross society of China was raising money or recruiting volunteers for the victims and were asked to indicate their intentions. A 7-point scale was used to measure their donation intentions ( 1 = strongly unwilling; $7=$ strongly willing) which was adapted from Macdonnell and White [13]. In the time donation condition, participants were asked to indicate their intentions to donate time by rating the item "The organization is now recruiting volunteers from the community for the project. How likely are you to spend time on volunteering?". In the money donation condition, participants were asked to indicate their intentions to donate money by rating the item "The organization is now raising money from the community for the project. How likely are you to donate money for the project?". To ensure that participants have certain financial resources to donate, participants were told that they could get some money reward for participating in this experiment before they indicated their donation intentions.

Finally, participants were asked to provide demographic information including gender, age and education. They were also asked whether they understood the purpose of the experiment.

\subsection{Results}

\subsubsection{Reliability and Validity Test}

None of the participants reported the true purpose of the study. Cronbach's alpha coefficients for the warmth and competence scale were 0.89 and 0.84 , respectively, both of which are greater than the threshold 0.70 . This indicated that warmth and competence scale have good aggregation validity and content validity.

\subsubsection{Manipulation Check}

The result of Shapiro-Wilk test indicated that the data were normally distributed in both experimental groups $\left(p_{\text {warm }}=0.98, p_{\text {competent }}=0.07\right.$; both $\left.p>0.05\right)$. A one-way ANOVA was used to check the effectiveness of advertising appeal manipulation. Results showed that exposure to different appeals resulted in significantly difference between the level of perceived warmth and perceived competence. Specifically, participants in the warm appeal condition $\left(\mathrm{M}_{\mathrm{warm}}=4.53, \mathrm{SD}=1.49\right)$ perceived advertising as warmer than those in the competent appeal condition $\left(\mathrm{M}_{\text {competent }}=3.84\right.$, $\mathrm{SD}=1.45 ; \mathrm{F}(1147)=8.23, p<0.01)$. Participants in the competent appeal condition $\left(\mathrm{M}_{\text {competent }}=5.15\right.$, $\mathrm{SD}=1.33)$ perceived advertising as more competent than those in the warm appeal condition $\left(\mathrm{M}_{\mathrm{warm}}=4.00, \mathrm{SD}=1.48 ; \mathrm{F}(1147)=25.26, p<0.001\right)$. Therefore, the manipulation was effective.

\subsubsection{Hypotheses Test}

To test the effect of different advertising appeals on donation intentions of different resources, a 2 (advertising appeal: warm vs. competent) $\times 2$ (donation type: time vs. money) ANOVA on donation intention was conducted. Results revealed that neither the main effects of appeal type $(\mathrm{F}(1145)=1.01$, $p>0.1)$ nor donation type was significant $(\mathrm{F}(1145)=0.00, p>0.1)$. However, the interaction between appeal type and donation type was significant $(\mathrm{F}(1145)=11.18, p<0.001)$. To further examine the two-way interaction effect, we ran simple-effect analyses. Results showed that in the warm appeal condition, participants' intentions to donate time $\left(\mathrm{M}_{\text {time }}=4.86, \mathrm{SD}=1.57\right)$ were significantly higher than to donate money $\left(\mathrm{M}_{\text {money }}=4.03, \mathrm{SD}=1.57 ; \mathrm{F}(1146)=5.32, p<0.05\right)$. In contrast, in the competent appeal condition, participants' intentions to donate money $\left(\mathrm{M}_{\text {money }}=4.62, \mathrm{SD}=1.33\right)$ were significantly 
higher than to donate time $\left(\left(\mathrm{M}_{\text {time }}=3.76, \mathrm{SD}=1.64 ; \mathrm{F}(1146)=6.22, p<0.05\right)\right.$ (see Figure 1$)$. Therefore, H1a and H1b were supported.

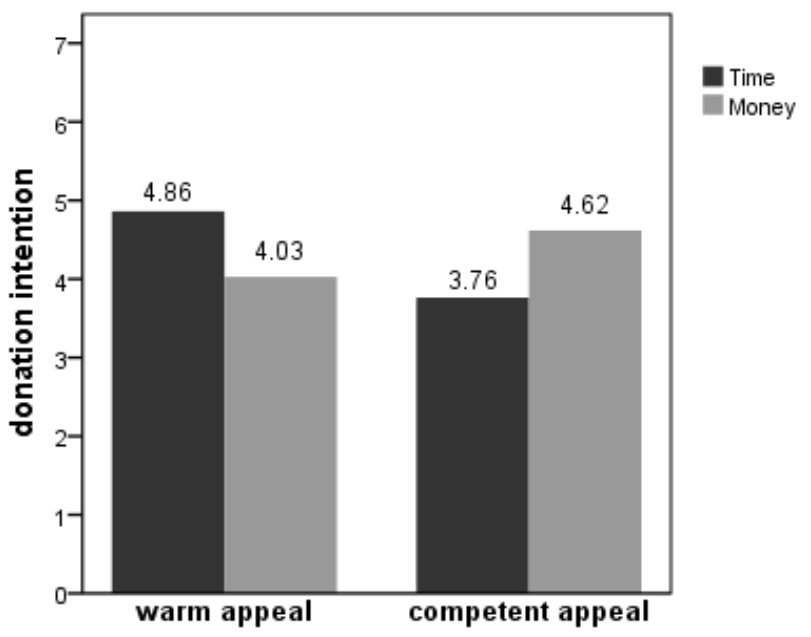

Figure 1. The interaction between appeal type and donation type.

\subsection{Discussion}

Study 1 found that the advertising appeals had a significant influence on the donation intentions of different resources. In particular, advertising with a warm appeal was more effective in increasing the intentions to donate time, whereas advertising with a competent appeal was more effective in increasing the intentions to donate money.

Although Study 1 provided preliminary support for H1a and H1b, there were some deficiencies. For example, given that advertising is often comprised of a text description and picture in reality, the experimental materials in Study 1 were relatively monotonous, because only a text description was included in the advertising. Thus, experimental stimuli were modified in Study 2. Moreover, little is known about how advertising appeals impact individual donation intentions, which will also be discussed in Study 2.

\section{Study 2: The Mediating Role of Social Connectedness and Competitive Orientation}

The aims of Study 2 were twofold. First, in order to improve the validity of the experiment, we made some modifications to the experimental stimuli based on Study 1 . We included a combination of text descriptions and pictures in the advertising as experimental stimuli and switched the theme of charitable donation project. We examined the main effect again in Study 2. Second, we sought to reveal the underlying mechanism in the influence of advertising appeals on donation intentions of different resources. The mediating roles of social connectedness and competitive orientation were tested in Study 2.

\subsection{Experimental Design and Subjects}

A 2 (advertising appeal: warm vs. competent) $\times 2$ (donation type: time vs. money) between-subjects quasi-experiment design was used in this study. Participants were randomly assigned to one of the four conditions. Consistent with Study 1, we selected Red Cross society of China, the organization which participants were most familiar with, as the charitable organization in the experiment, but we changed the theme of charitable project from disaster relief into medical health. More specifically, we selected cancer as the topic, following the study of Brunel and Nelson [8]. Brunel and Nelson pointed out that appeal for cancer promotes a cause that is generally accepted as worthwhile instead of inducing some controversy (e.g., abortion) [8]. As a result, we can avoid some polarized responses during the experiment. 
We conducted another experiment in the library of Jinan University in March 2019, where questionnaires were distributed and collected. Two hundred students participated in exchange for payment. After removing 16 participants for failing to complete the questionnaire as requested, a total of 184 valid questionnaires were collected (46 for warm-time condition, 45 for warm-money condition, 47 for competence-time condition, 46 for competence-money condition). Among them, the age of participants is mainly between 18 and 25 years old, accounting for $78.3 \%$. There were 102 females (55.4\%) and 82 males (44.6\%); 55 undergraduates (29.9\%), 116 graduate students $(63.0 \%)$ and 13 others $(7.1 \%)$.

\subsection{Experimental Procedures}

First, participants were required to read the advertising and then rate the advertising on a warmth-competence scale. We included both a text description and pictures in the advertising so as to make the feeling of warmth and competence more intense after viewing the advertisement. In order to prevent the influence of color on experiment, we used pictures printed in grayscale (black and white). Following Peng and Bi, we varied the pictures and advertising slogans according to different advertising appeals [62]. Specifically, in the warm appeal condition, a picture of a handshake was used in the advertising with a slogan as shown in Figure 2a; in the competent appeal condition, a picture of a fist was used in the advertising with a slogan as shown in Figure $2 b$.

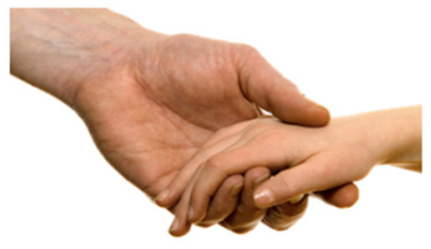

We need humanistic care, social warmth and sincere love. Please give out your helping hands!

Red Cross Society of China

(a)

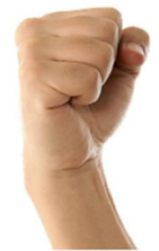

We need courage, confidence and ability to overcome difficulties. Please give out your powerful hands!

Red Cross Society of China

Figure 2. Advertising with (a) warm appeals and (b) competent appeals.

After viewing the advertising, participants were asked to rate the advertising on a warmth-competence scale adapted from Kervyn et al. for manipulation check [32]. Specifically, they were required to indicate the degree to which they perceived the appeal they had viewed was warm (three items: warm/friendly/sincere) and competent (three items: competent/powerful/confident) on 7 -point scales $(1=$ not at all, $7=$ very much).

Then, participants were asked to indicate their donation intentions using the same 7-point scales as in Study 1. Specifically, in the money condition, they indicated how likely they were to donate money; and in the time condition, they indicated how likely they were to volunteer their time.

Next, participants were asked to indicate the extent to which they agreed with the items measuring social connectedness and competitive orientation on 7-point scales $(1=$ strongly disagree, $7=$ strongly agree). The measure of social connectedness was adapted from Reed et al. and Lee and Robbins, including three items "I feel I am closely connected to others", "I feel like I really understand others" and "I think I create a strong bond with others" [20,63]. The measure of competitive orientation was adapted from Johnson and Norem-Hebeisen, including two items "I like to do better work than others" and "I work to get better performance than others do" [64].

Finally, participants were asked to provide demographic information including gender, age and education. They were also asked whether they understood the purpose of the experiment. 


\subsection{Results}

\subsubsection{Reliability and Validity Test}

None of the participants reported the true purpose of the study. Cronbach's alpha coefficients for the warmth and competence scale were 0. 91 and 0.86, respectively, and Cronbach's alpha of social connectedness and competence scale were 0.87 and 0.82 , respectively. All of these results were greater than the threshold of 0.70 , indicating that the scales had internal reliability.

\subsubsection{Manipulation Check}

The result of the Shapiro-Wilk test indicated that the data were normally distributed in both experimental groups $\left(p_{\text {warm }}=0.85, p_{\text {competent }}=0.22\right.$; both $p>0.05$ ). A one-way ANOVA was used to check the effectiveness of advertising appeal manipulation. Results showed that exposure to different appeals resulted in a significant difference in the level of perceived warmth and perceived competence. Specifically, participants in the warm appeal condition $\left(\mathrm{M}_{\mathrm{warm}}=4.66, \mathrm{SD}=1.58\right)$ perceived advertising as warmer than those in the competent appeal condition $\left(\mathrm{M}_{\text {competent }}=3.85, \mathrm{SD}=1.50 ; \mathrm{F}(1182)=12.83\right.$, $p<0.001)$. Participants in the competent appeal condition $\left(\mathrm{M}_{\text {competent }}=5.02, \mathrm{SD}=1.42\right)$ perceived advertising as more competent than those in the warm appeal condition $\left(\mathrm{M}_{\mathrm{warm}}=4.02, \mathrm{SD}=1.50\right.$; $\mathrm{F}(1182)=21.30, p<0.001)$. Therefore, the manipulation was effective.

\subsubsection{Hypotheses Test of Main Effect}

In order to test the effect of different advertising appeals on donation intentions of different resources, we conducted a 2 (appeal: warm vs. competent) $\times 2$ (donation type: time vs. money) ANOVA on donation intentions. Results revealed that neither the main effects of appeal type (F $(1180)=0.47, p>0.1)$ nor donation type were significant $(\mathrm{F}(1180)=0.00, p>0.1)$. However, the interaction between appeal type and donation type was significant $(\mathrm{F}(1180)=9.92, p<0.01)$. Results of simple-effect analyses showed that in the warm appeal condition, participants indicated significantly different intentions to donate time and money, such that participants were more willing to donate time $\left(\mathrm{M}_{\text {time }}=4.67, \mathrm{SD}=1.74\right)$ than donate money $\left(\mathrm{M}_{\text {money }}=3.91, \mathrm{SD}=1.58 ; \mathrm{F}(1181)=4.72, p<0.05\right)$ after viewing the warm advertising. In contrast, in the competent appeal condition, participants indicated significantly different intentions to donate time and money, such that participants were more willing to donate money $\left(\mathrm{M}_{\text {money }}=4.52, \mathrm{SD}=1.59\right)$ than donate time $\left(\mathrm{M}_{\text {time }}=3.72, \mathrm{SD}=1.80 ; \mathrm{F}(1181)=5.28\right.$, $p<0.05)$-see Figure 3. Therefore, H1a and H1b were supported.

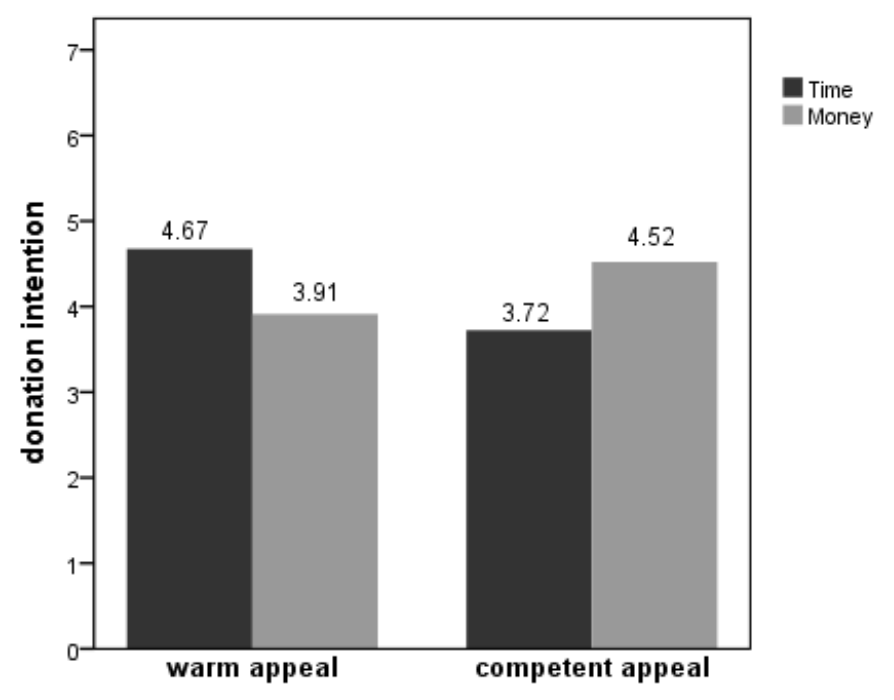

Figure 3. The interaction between appeal type and donation type. 


\subsubsection{The Mediation Analysis of Social Connectedness and Competitive Orientation}

In order to test the mediating role of social connectedness and competitive orientation, we conducted bootstrapped mediation analysis following the procedure of Zhao et al. [65]. We used model 8 in the mediation analysis with 5000 samples and 95\% confidence intervals [66,67]. Result from the mediation analysis of social connectedness and competitive orientation showed that both social connectedness and competitive orientation mediate the influence of the interaction between advertising appeal and resource type on donation intentions (social connectedness: $\beta=0.239, \mathrm{CI}=0.0180$ to 0.5981 ; competitive orientation: $\beta=0.364, \mathrm{CI}=0.0324$ to 0.8204 ).

Further analysis revealed that in the warm appeal condition, mediation through social connectedness was significant ( $\beta=0.215, \mathrm{CI}=0.0440$ to 0.4826 ), but mediation through competitive orientation was not significant ( $\beta=-0.067, C I=-0.3387$ to 0.1595 ). These indicated that social connectedness mediates the influence of warm appeal on donation intention of time, supporting $\mathrm{H} 2 \mathrm{a}$. In contrast, in the competent appeal condition, mediation through competitive orientation was significant $(\beta=-0.430, C I=-0.8390$ to -0.1617$)$, but mediation through social connectedness was not significant ( $\beta=-0.024, C I=-0.2240$ to 0.1519 ). These results indicated that competitive orientation mediated the influence of competent appeal on donation intention of money, supporting H2b.

\subsection{Discussion}

Study 2 modified the advertising material and charitable project based on Study 1, thus increasing the validity and applicability of the experimental findings. The findings of Study 2 provided further support for $\mathrm{H} 1 \mathrm{a}$ and $\mathrm{H} 1 \mathrm{~b}$, suggesting that advertising appeals have a significant influence on intentions to donate different resources. Specifically, in the warm appeal condition, individuals were more willing to donate time relative to money, while in the competent appeal condition individuals were more willing to donate money relative to time. Moreover, Study 2 revealed the underlying mechanism of consumers' donation of time and money under different advertising appeal conditions, such that social connectedness and competitive orientation played mediating roles in the relationship between adverting appeals and donation intentions of different resources. Specifically, social connectedness mediated the effect of a warm appeal on time donation intentions, whereas competitive orientation mediated the effect of competent appeals on money donation intention.

\section{Conclusions and Discussion}

\subsection{Conclusions}

By applying two fundamental dimensions of social cognition into charitable advertising, we identified two kinds of charitable advertising appeals, namely warm appeal and competent appeal. From the perspective of trait activation theory, we examined the relative effectiveness of different appeal to time donation and money donation. The results showed that different appeals significantly influenced donation intentions of time and money. Warm appeals were more effective in increasing time donation intentions, whereas competent appeals were more effective in increasing money donation. Moreover, we revealed the underlying mechanism between advertising appeal and donation intentions of time and money by examining the mediating roles of social connectedness and competitive orientation. Social connectedness mediated the relationship between warm appeals and time donation intentions, suggesting that warm advertising appeals strengthened social connectedness, which in turn increased time donation intentions. In contrast, competitive orientation mediated the relationship between competent appeals and money donation intentions, suggesting that competent advertising appeals strengthen competitive orientation, which in turn increased money donation intentions.

\subsection{Theoretical Implication}

This research provides several theoretical contributions. First, this research extends social cognition into charitable context, enriching the literature on charitable advertising. Warmth and competence 
are two fundamental dimensions of social cognition. Although these dimensions have been adopted in business advertising research which aims to increase purchase intentions [30], few studies have focused on both dimensions in charitable advertising. Additionally, some studies have only focused on the warmth appeals, which they regard as a kind of positive emotional appeal, with negative emotional appeals being regarded as the negative ones $[12,14]$. Based on the two fundamental dimensions of social cognition, we identified two types of appeals in charitable advertisings, namely, warm appeal and competent appeal. By examining their roles on donation intentions of different resources, we demonstrated the best advertising strategies in different situations. Specifically, a warm appeal is more effective in attracting time donation, while a competent appeal is more effective in attracting money donation.

Second, this research enriches the literature on time and money in the charitable context, providing new perspectives to study factors influencing charitable donation. Time and money are psychologically different, resulting in the difference of individuals' perceptions and behaviors. Most of the previous studies have discussed either time donation or money donation and focused on the elements influencing the donation intention of one kind of resources [16-20]. Few studies have considered time donation and money donation simultaneously $[13,21]$. For example, Zhou et al. focus on money donation and demonstrate that money anthropomorphism can promote monetary donation behaviors, but it cannot enhance other types of charitable giving, such as signature provision [18]. Macdonnell and White focus on both money and time donation, and point out that a more concrete framing of the charitable cause will be more effective to increase money donation intention, whereas a more abstract frame will be more effective to increase time donation intention [13]. We propose that, since time and money are psychologically different, it is necessary to differentiate between money donation and time donation in order to determine the best advertising strategies, respectively. By introducing two fundamental dimensions of social cognition (i.e., warmth and competence), we examine the role of warm appeal and competent appeal in donation intentions of different resources. The findings of this research support our propositions.

Third, this research reveals the underlying mechanism in the influence of different advertising appeals on donation intentions of different resources. Although many studies have discussed the role of advertising strategies in donation intentions [13,21], few have explored the underlying mechanism of the process. For example, although Macdonnell and White discussed the influence of concrete and abstract appeals on time and money donation intention, they did not explore the mechanism underlying the relationship [13]. This research develops a more complete framework on how advertising appeals affect individuals' donation intentions by examining the mediating roles of social connectedness and competitive orientation. Specifically, we found that social connectedness mediates the relationship between warm appeal and time donation intention, whereas competitive orientation mediates the relationship between competent appeal and money donation intention.

\subsection{Practical Implication}

The findings of this research have important and practical implications for non-profit organizations to develop charitable advertising strategies. Effective advertising strategies are of great importance in promoting the participation of individuals, due to a growing need, shrinking governmental support, and intensifying competition between organizations. The findings of this research provide some guidelines. First, charitable organizations can use different kinds of advertising appeals to increase individuals' intentions of different resources. This research showed that warm appeals are more effective in increasing time donation intentions, whereas competent appeals are more effective in increasing money donation intentions. Consequently, charitable organizations can vary their advertising strategies according to their target donation type, so as to increase the effectiveness of advertising. When charitable organizations attempt to appeal to individuals to donate money, they can design the advertisings emphasizing warmth, such as by using the warm words "love, kind, moral, caring" in the slogan. In contrast, when charitable organizations attempt to appeal to individuals to 
volunteer time, they can design advertisings emphasizing competence, such as by using the competent words "confident, powerful, courage, ability" in the slogan. Second, this research indicated that social connectedness mediated the relationship between a warm appeal and time donation intention, while competitive orientation mediated the relationship between a competent appeal and money donation intention. This can also provide charitable organizations with some guidelines to design advertising. For example, when charitable organizations appeal for a time donation, they can design the advertising to emphasize both warmth and social connectedness, such as by presenting an image depicting the situation of helping others, which enables individuals to have more intense feelings. With the stronger influence of these feelings, it is easier for charitable organizations to increase individuals' time donation intentions. Similarly, by strengthening the competitive orientation in the competent appeal to emphasize the benefit of the donation, it can be easier for charitable organizations to increase individuals' money donation intentions.

The findings of this research have important practical implications for profit organizations. Nowadays, many companies have adopted cause-related marketing as an effective marketing tool to improve the firm's social image and boost their sales [68]. When companies decide to carry out cause-related marketing, they will contribute a specified amount from their sales to social cause in marketing activities [69]. Both companies and charitable organizations can benefit from cause-related marketing. This research provides some implication for companies to implement cause-related marketing. According to the findings in this research, through considering the role of competent appeals in money donation intentions, companies can design the product advertisings with competent appeal in cause-related marketing in order to promote an individual's participation and increase their intention to spend money on companies' products and services. Therefore, the effectiveness of cause-related marketing can be enhanced, which in turn benefits the sponsoring companies.

\subsection{Limitations and Further Research Direction}

There are a few limitations in this research and we propose some further research directions. First, we only discussed money and time donation in this research. In reality, however, there are many other donation types, such as goods donation and blood donation. Goods donation are associated with communality and prosociality [70]. Blood donations are faced with more reluctance from donators [71]. As different resources can prime different psychological processes and subsequently influence an individual's behaviors and donation intentions, further research can explore effective advertising to increasing intentions of other resources.

Second, there are many kinds of advertising appeal in reality. In this research, we extended two fundamental dimensions of social cognition into charitable context and identified two kinds of appeals-warm appeals and competent appeal. We also compared the effects of these appeals to time and money donation. For the purpose of increasing donation intentions and promoting social sustainable development, more kinds of appeals are worth exploring in a future study.

Third, boundary conditions were not discussed in this research. It is possible that boundary conditions can reverse the main effect. Therefore, boundary conditions can be explored in future research to increase the applicability of the findings. For example, charity projects, such as the emergency of the project and the familiarity of the project, can exert some influence. Charitable projects for sudden event (e.g., an earthquake) are more attention-grabbing than continuous events (e.g., education support in poverty area). The familiarity of charity events (e.g., breast cancer, which is usually unfamiliar for individuals) can affect an individual's information reception and processing, which in turn influences their donation intentions. In addition, individual characteristics can also have a significant influence because of the difference in psychological perception and behavior tendency. Characteristics such as moral identity, self-construal, construal level can be considered in future research. Whether these moderators can influence the effect of a warm appeal and a competence appeal on time and money donation requires further examination. 
Fourth, most of the experiment subjects in the paper are university students. They are of similar age and education background, resulting in the consistent tendency in behaviors. This may decrease the representative power of sampling subjects. In reality, donors come from different age groups and different occupations. Consequently, in order to enhance the external validity of the experiment, future research can extend sampling subjects to verify the findings.

Author Contributions: Conceptualization, Y.Z., C.L., and J.Y.; Methodology, Y.Z. and C.L.; Validation, Y.Z., C.L., and J.Y.; Data curation, J.Y.; Writing, Y.Z., C.L., and J.Y.; Visualization, C.L.; Supervision, Y.Z.; Project administration, Y.Z.; Funding acquisition, Y.Z.

Funding: This research was funded by the Natural Science Foundation of Guangdong Province, China (2018A0303130192); Jinan University Management School Funding Program, China (NO. GY 18005).

Conflicts of Interest: The authors declare no conflict of interest.

\section{References}

1. Park, K.; Ryu, G. The effect of regulatory focus on individuals' donation behavior. Sustainability 2018, 10, 760. [CrossRef]

2. Park, E.Y.; Rhee, J.H. Who Clicks on Online Donation? Understanding the Characteristics of SNS Users during Participation in Online Campaigns. Sustainability 2019, 11, 3674. [CrossRef]

3. Chang, C. Guilt regulation: The relative effects of altruistic versus egoistic appeals for charity advertising. J. Advert. 2014, 43, 211-227. [CrossRef]

4. See the Numbers-Giving USA 2018 Infographic. Available online: https://givingusa.org/tag/giving-usa-2018 (accessed on 7 October 2019).

5. Sudhir, K.; Roy, S.; Cherian, M. Do sympathy biases induce charitable giving? The effects of advertising content. Mark. Sci. 2016, 35, 849-869. [CrossRef]

6. The Annual Report on China's Charitable Donation. 2017. Available online: http://www.charityalliance.org. cn/givingchina/index.jhtml (accessed on 7 October 2019).

7. Reed, A.; Aquino, K.; Levy, E. Moral identity and judgments of charitable behaviors. J. Mark. 2007, 71, 178-193. [CrossRef]

8. Brunel, F.F.; Nelson, M.R. Explaining gendered responses to "help-self" and "help-others" charity ad appeals: The mediating role of world-views. J. Advert. 2000, 29, 15-28. [CrossRef]

9. White, K.; Peloza, J. Self-benefit versus other-benefit marketing appeals: Their effectiveness in generating charitable support. J. Mark. 2009, 73, 109-124. [CrossRef]

10. Kulow, K.; Kramer, T. In pursuit of good karma: When charitable appeals to do right go wrong. J. Consum. Res. 2016, 43, 334-353. [CrossRef]

11. Chang, C.-T.; Lee, Y.-K. Effects of message framing, vividness congruency and statistical framing on responses to charity advertising. Int. J. Advert. 2010, 29, 195-220. [CrossRef]

12. Erlandsson, A.; Nilsson, A.; Västfjäll, D. Attitudes and donation behavior when reading positive and negative charity appeals. J. Nonprofit Public Sect. Mark. 2018, 30, 444-474. [CrossRef]

13. Macdonnell, R.; White, K. How construals of money versus time impact consumer charitable giving. J. Consum. Res. 2015, 42, 551-563. [CrossRef]

14. Haynes, M.; Thornton, J.; Jones, S.C. An exploratory study on the effect of positive (warmth appeal) and negative (guilt appeal) print imagery on donation behavior in animal welfare. In Proceedings of the Marketing Accountabilities and Responsibilities: ANZMAC 2004 Conference, School of Marketing and International Business, Victoria University of Wellington, Wellington, New Zealand, 29 November-1 December 2004.

15. Fiske, S.T.; Cuddy, A.J.; Glick, P. Universal dimensions of social cognition: Warmth and competence. Trends Cogn. Sci. 2007, 11, 77-83. [CrossRef] [PubMed]

16. Kemp, E.; Kennett-Hensel, P.A.; Kees, J. Pulling on the heartstrings: Examining the effects of emotions and gender in persuasive appeals. J. Advert. 2013, 42, 69-79. [CrossRef]

17. Choi, J.; Rangan, P.; Singh, S.N. Do cold images cause cold-heartedness? The impact of visual stimuli on the effectiveness of negative emotional charity appeals. J. Advert. 2016, 45, 417-426. [CrossRef]

18. Zhou, X.; Kim, S.; Wang, L. Money helps when money feels: Money anthropomorphism increases charitable giving. J. Consum. Res. 2018, 45, 953-972. [CrossRef] 
19. Winterich, K.P.; Zhang, Y. Accepting inequality deters responsibility: How power distance decreases charitable behavior. J. Consum. Res. 2014, 41, 274-293. [CrossRef]

20. Reed, I.; Kay, A.; Finnel, S.; Aquino, K.; Levy, E. I don't want the money, I just want your time: How moral identity overcomes the aversion to giving time to prosocial causes. J. Personal. Soc. Psychol. 2016, 110, 435-457. [CrossRef]

21. Kim, N. Advertising strategies for charities: Promoting consumers' donation of time versus money. Int. J. Advert. 2014, 33, 707-724. [CrossRef]

22. Vohs, K.D. Money priming can change people's thoughts, feelings, motivations, and behaviors: An update on 10 years of experiments. J. Exp. Psychol. Gen. 2015, 144, e86-e93. [CrossRef]

23. Rudd, M.; Catapano, R.; Aaker, J. Making Time Matter: A Review of Research on Time and Meaning. J. Consum. Psychol. 2019, 29, 680-702. [CrossRef]

24. Schuhwerk, M.E.; Lefkoff-Hagius, R. Green or non-green? Does type of appeal matter when advertising a green product? J. Advert. 1995, 24, 45-54. [CrossRef]

25. Holbrook, M.B.; Batra, R. Assessing the role of emotions as mediators of consumer responses to advertising. J. Consum. Res. 1987, 14, 404-420. [CrossRef]

26. Nelson, M.R.; Brunel, F.F.; Supphellen, M.; Manchanda, R.V. Effects of culture, gender, and moral obligations on responses to charity advertising across masculine and feminine cultures. J. Consum. Psychol. 2006, 16, 45-56. [CrossRef]

27. Small, D.A.; Verrochi, N.M. The face of need: Facial emotion expression on charity advertisements. J. Mark. Res. 2009, 46, 777-787. [CrossRef]

28. Cryder, C.E.; Loewenstein, G.; Seltman, H. Goal gradient in helping behavior. J. Exp. Soc. Psychol. 2013, 49, 1078-1083. [CrossRef]

29. Erlandsson, A.; Björklund, F.; Bäckström, M. Emotional reactions, perceived impact and perceived responsibility mediate the identifiable victim effect, proportion dominance effect and in-group effect respectively. Organ. Behav. Hum. Decis. Process. 2015, 127, 1-14. [CrossRef]

30. Zawisza, M.; Pittard, C. When do warmth and competence sell best? The "golden quadrant" shifts as a function of congruity with the product type, targets' individual differences, and advertising appeal type. Basic Appl. Soc. Psychol. 2015, 37, 131-141. [CrossRef]

31. Aaker, D.A.; Stayman, D.M.; Hagerty, M.R. Warmth in advertising: Measurement, impact, and sequence effects. J. Consum. Res. 1986, 12, 365-381. [CrossRef]

32. Kervyn, N.; Fiske, S.T.; Malone, C. Brands as intentional agents framework: How perceived intentions and ability can map brand perception. J. Consum. Psychol. 2012, 22, 166-176. [CrossRef]

33. Tett, R.P.; Burnett, D.D. A personality trait-based interactionist model of job performance. J. Appl. Psychol. 2003, 88, 500-517. [CrossRef]

34. Oyserman, D.; Lee, S.W.S. Priming 'culture': Culture as situated cognition. In Handbook of Cultural Psychology; Kitayama, S., Cohen, D., Eds.; Guilford Press: New York, NY, USA, 2007; pp. 255-279.

35. Cuddy, A.J.; Fiske, S.T.; Glick, P. Warmth and competence as universal dimensions of social perception: The stereotype content model and the BIAS map. Adv. Exp. Soc. Psychol. 2008, 40, 61-149.

36. Mogilner, C. The pursuit of happiness: Time, money, and social connection. Psychol. Sci. 2010, 21, $1348-1354$. [CrossRef] [PubMed]

37. Grossmann, I.; Varnum, M.E. Social class, culture, and cognition. Soc. Psychol. Personal. Sci. 2011, 2, 81-89. [CrossRef]

38. Kraus, M.W.; Park, J.W. The undervalued self: Social class and self-evaluation. Front. Psychol. 2014, 5, 1404. [CrossRef] [PubMed]

39. Saini, R.; Monga, A. How I decide depends on what I spend: Use of heuristics is greater for time than for money. J. Consum. Res. 2008, 34, 914-922. [CrossRef]

40. Zauberman, G.; Lynch, J.G., Jr. Resource slack and propensity to discount delayed investments of time versus money. J. Exp. Psychol. Gen. 2005, 134, 23-37. [CrossRef] [PubMed]

41. Okada, E.M.; Hoch, S.J. Spending time versus spending money. J. Consum. Res. 2004, 31, 313-323. [CrossRef]

42. Leclerc, F.; Schmitt, B.H.; Dube, L. Waiting time and decision making: Is time like money? J. Consum. Res. 1995, 22, 110-119. [CrossRef]

43. Mogilner, C.; Aaker, J. “The time vs. money effect”: Shifting product attitudes and decisions through personal connection. J. Consum. Res. 2009, 36, 277-291. [CrossRef] 
44. Soman, D. The mental accounting of sunk time costs: Why time is not like money. J. Behav. Decis. Mak. 2001, 14, 169-185. [CrossRef]

45. Spiller, S.A.; Lynch, J.G. Individuals exhibit the planning fallacy for time but not for money. SSRN 2010. [CrossRef]

46. Lee, R.M.; Robbins, S.B. Measuring belongingness: The social connectedness and the social assurance scales. J. Couns. Psychol. 1995, 42, 232-241. [CrossRef]

47. Cross, S.E.; Bacon, P.L.; Morris, M.L. The relational-interdependent self-construal and relationships. J. Personal. Soc. Psychol. 2000, 78, 791-808. [CrossRef]

48. Karremans, J.C.; Van Lange, P.A.; Holland, R.W. Forgiveness and its associations with prosocial thinking, feeling, and doing beyond the relationship with the offender. Personal. Soc. Psychol. Bull. 2005, 31, 1315-1326. [CrossRef] [PubMed]

49. Duclos, R.; Barasch, A. Prosocial behavior in intergroup relations: How donor self-construal and recipient group-membership shape generosity. J. Consum. Res. 2014, 41, 93-108. [CrossRef]

50. Cojuharenco, I.; Cornelissen, G.; Karelaia, N. Yes, I can: Feeling connected to others increases perceived effectiveness and socially responsible behavior. J. Environ. Psychol. 2016, 48, 75-86. [CrossRef]

51. Gino, F.; Mogilner, C. Time, money, and morality. Psychol. Sci. 2014, 25, 414-421. [CrossRef] [PubMed]

52. Chen, X.-P.; Xie, X.; Chang, S. Cooperative and competitive orientation among Chinese people: Scale development and validation. Manag. Organ. Rev. 2011, 7, 353-379. [CrossRef]

53. McClintock, C.G.; Allison, S.T. Social value orientation and helping behavior 1. J. Appl. Soc. Psychol. 1989, 19, 353-362. [CrossRef]

54. Knight, G.P.; Kagan, S. Development of prosocial and competitive behaviors in Anglo-American and Mexican-American children. Child Dev. 1977, 48, 1385-1394. [CrossRef]

55. Cox, T.H.; Lobel, S.A.; McLeod, P.L. Effects of ethnic group cultural differences on cooperative and competitive behavior on a group task. Acad. Manag. J. 1991, 34, 827-847.

56. Roux, C.; Goldsmith, K.; Bonezzi, A. On the psychology of scarcity: When reminders of resource scarcity promote selfish (and generous) behavior. J. Consum. Res. 2015, 42, 615-631. [CrossRef]

57. Utz, S.; Van Lange, P.A.; Green, E.; Waldzus, S.; Bovina, I. Mary honest always friendly and is: Can scrambled sentences enhance prosocial motivation? Represent. Res. Soc. Psychol. 2005, 28, 59-70.

58. Tauer, J.M.; Harackiewicz, J.M. The effects of cooperation and competition on intrinsic motivation and performance. J. Personal. Soc. Psychol. 2004, 86, 849-861. [CrossRef] [PubMed]

59. Messick, D.M.; Allison, S.T.; Samuelson, C.D. Framing and communication effects on group members' responses to environmental and social uncertainty. In Applied Behavioral Economics; Maital, S., Ed.; New York University Press: New York, NY, USA, 1988; Volume 2, pp. 677-700.

60. Van Kleef, G.A.; De Dreu, C.K. Longer-term consequences of anger expression in negotiation: Retaliation or spillover? J. Exp. Soc. Psychol. 2010, 46, 753-760. [CrossRef]

61. Stapel, D.A.; Koomen, W. Competition, cooperation, and the effects of others on me. J. Personal. Soc. Psychol. 2005, 88, 1029-1038. [CrossRef]

62. Pang, J.; Bi, S. Effects of Congruency between Advertising Appeal and Country-of-Origin Stereotype on Brand Attitude. Acta Psychol. Sin. 2015, 47, 406-416. [CrossRef]

63. Lee, R.M.; Robbins, S.B. The relationship between social connectedness and anxiety, self-esteem, and social identity. J. Couns. Psychol. 1998, 45, 338-345. [CrossRef]

64. Johnson, D.W.; Norem-Hebeisen, A.A. A measure of cooperative, competitive, and individualistic attitudes. J. Soc. Psychol. 1979, 109, 253-261. [CrossRef]

65. Zhao, X.; Lynch, J.G., Jr.; Chen, Q. Reconsidering Baron and Kenny: Myths and truths about mediation analysis. J. Consum. Res. 2010, 37, 197-206. [CrossRef]

66. Preacher, K.J.; Rucker, D.D.; Hayes, A.F. Addressing moderated mediation hypotheses: Theory, methods, and prescriptions. Multivar. Behav. Res. 2007, 42, 185-227. [CrossRef] [PubMed]

67. Hayes, A.F. An Introduction to Mediation, Moderation and Conditional Process Analysis: A Regression-Based Approach; Guilford Press: New York, NY, USA, 2013.

68. Grau, S.L.; Folse, J.A.G. Cause-related marketing (CRM): The influence of donation proximity and message-framing cues on the less-involved consumer. J. Advert. 2007, 36, 19-33. [CrossRef] 
69. Varadarajan, P.R.; Menon, A. Cause-related marketing: A coalignment of marketing strategy and corporate philanthropy. J. Mark. 1988, 52, 58-74. [CrossRef]

70. Gershon, R.; Cryder, C. Goods donations increase charitable credit for low-warmth donors. J. Consum. Res. 2017, 45, 451-469. [CrossRef]

71. Armitage, C.J.; Conner, M. Social cognitive determinants of blood donation. J. Appl. Soc. Psychol. 2001, 31, 1431-1457. [CrossRef]

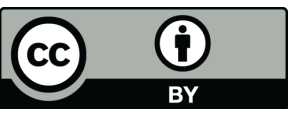

(C) 2019 by the authors. Licensee MDPI, Basel, Switzerland. This article is an open access article distributed under the terms and conditions of the Creative Commons Attribution (CC BY) license (http://creativecommons.org/licenses/by/4.0/). 